\title{
Variability of ankle and brachial systolic pressures in the measurement of atherosclerotic peripheral arterial disease
}

\author{
F G R FOWKES, ${ }^{1}$ E HOUSLEY, ${ }^{2} \mathrm{C}$ C A MACINTYRE, ${ }^{3} \mathrm{R}$ J PRESCOTT, ${ }^{3}$ AND \\ C V RUCKLEY ${ }^{2}$ \\ From the Department of Community Medicine, ${ }^{1}$ University of Edinburgh; Peripheral Vascular Clinic, ${ }^{2}$ Royal \\ Infirmary of Edinburgh; and Medical Statistics Unit, ${ }^{3}$ University of Edinburgh
}

SUMMARY The aim of this study was to determine the variability of measurements of ankle and brachial systolic pressures and ankle brachial ratios in order to assess their suitability for use in epidemiological studies of arterial disease in the lower limbs. Thirty-six subjects had repeat measurements taken by four observers on two separate days using a Doppler probe and random zero sphygmomanometer. The variability in the measurement of ankle systolic pressure was comparable to that for brachial systolic pressure. The $95 \%$ confidence limits of one measurement of the ankle brachial ratio was estimated to be $\pm 16 \%$, reducing to $\pm 10 \%$ for the mean of four measurements taken by two observers on two days. Analysis of variance indicated that the variability in the measurement of ankle brachial ratios attributable to observers, days, timing of measurements on the same day, and repeat measurements was considerably less than the "biological" variability between subjects and between legs. These results suggest that repeatability of the ankle brachial ratio is such that a single measurement is suitable for most epidemiological studies of atherosclerotic peripheral arterial disease.

In the United Kingdom, atherosclerotic disease of the lower limbs is widespread throughout the adult population and causes considerable morbidity and mortality. By late middle age almost every adult has atherosclerotic lesions affecting their peripheral arteries, and in around $15 \%$ of men and $5 \%$ of women more than half the diameter of the lumen of a a major artery may be occluded. ${ }^{1}$ The prevalence of intermittent claudication in men aged 45 to 69 years is approximately $2 \%^{23}$ and in women aged $50-69$ years is $1.2 \% .^{3}$ In many patients, the disease is severe enough to warrant hospital admission. Each year in the United Kingdom, approximately 50000 patients are admitted with a principal diagnosis of peripheral arterial disease, and of those, over 15000 have major surgery, including amputations, with a mortality of around $10 \%{ }^{4}$

Epidemiological research into peripheral arterial disease has concentrated almost entirely on symptomatic subjects with intermittent claudication. Yet studies in the United States of America, ${ }^{5}$
Switzerland, ${ }^{6}$ Belgium, ${ }^{7}$ and Denmark ${ }^{8}$ suggest that severe asymptomatic disease is common and that at least $10 \%$ of the population by the age of 60 years has a major disruption to peripheral blood flow. Further research on asymptomatic subjects will require the use of non-invasive measurement techniques, which are of adequate validity and reliability.

In clinical practice, the ratio of ankle to brachial systolic pressure is used widely to assess peripheral arterial disease. The results of studies based on small numbers of subjects have suggested that a cut-off point for the ankle to brachial systolic pressure ratio of 0.9 is almost $95 \%$ sensitive in detecting angiogram positive disease and approaching $100 \%$ specific in excluding healthy subjects. ${ }^{9-14}$ Also, ratios would appear to correlate with the severity of disease. ${ }^{11} 1315$

But the variability in the measurement of ankle brachial pressure ratios has not been fully assessed. The aim of this study was to determine the extent and sources of such variability when measurements were taken by different observers on different occasions. 
Variability of ankle and brachial systolic pressures in the measurement of arterial disease

The potential for using this measurement in epidemiological studies could then be assessed.

\section{Method}

The study was conducted on 36 subjects aged 40-74 years in the Peripheral Vascular Clinic, Royal Infirmary of Edinburgh. Twenty four subjects with symptomatic peripheral arterial disease were selected from successive patients attending the peripheral vascular clinic; patients were excluded if they had severe disease manifest by previous amputation, gangrene, or pain at rest. Twelve subjects were "healthy" volunteers in that they did not give a history of intermittent claudication and their peripheral pulses were present; one of these 12 subjects was found subsequently to have disease and was excluded from the analysis. Subjects were invited to attend the peripheral vascular clinic on two afternoons approximately two weeks apart.

Four physiological measurement technicians were recruited specially to conduct the observations on the subjects. These four observers underwent intensive training in the peripheral vascular clinic until it was considered on subjective grounds that they were suitably skilled at taking the measurements.

The examination of each subject took place in one of two identical rooms in the clinic. The temperature of the rooms was continually checked and kept at between 20 and $23^{\circ} \mathrm{C}$. On arrival at the clinic the subject waited for at least 10 minutes in the waiting room, then entered the examination room, removed appropriate clothing, and rested on the examination couch for 10 minutes.

The right brachial systolic pressure was measured twice by an observer followed by the right ankle pressure (twice) and left ankle pressure (twice). Pressures in the arm and leg were measured using a random zero sphygmomanometer ${ }^{16}$ and blood flow was detected during deflation of the cuff by means of an auditory signal from a Doppler probe placed over the brachial and posterior tibial arteries. This technique for measuring blood pressure has been shown to relate closely to direct intra-arterial recordings. ${ }^{17} 18$

The subject then returned to the waiting room for approximately 40 minutes and had some light refreshment. On re-entering the examination room he/she had 10 minutes' rest followed by repetition of the tests by another observer. Two weeks later the subject had exactly the same routine except that the two observers were different from those present at the first visit. The diagram below summarises the pattern of measurements conducted on each subject during the study:

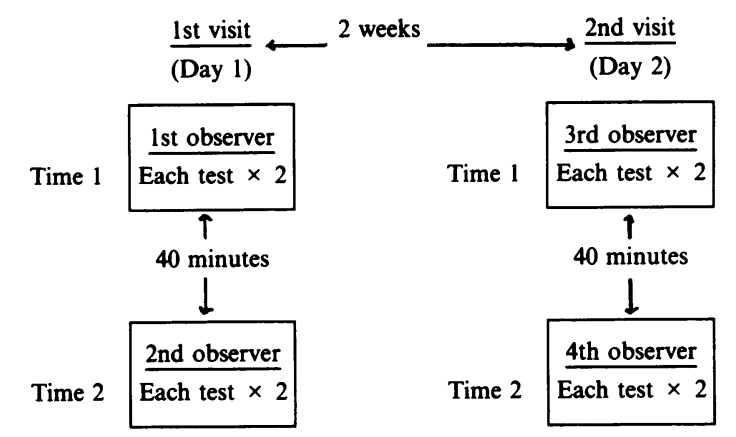

A sequence was drawn up so that each observer took measurements on both first and second visits and on first and second sets of measurements within visits. The design ensured comparability between observers with respect to any possible period and "carry over"effects. The subjects were allocated into the sequence based on their ability to attend appointment times at the clinic. The data from each set of measurements were recorded on a standard form by each observer who was blind to measurements by previous observers.

The principal aim of the data analysis was to examine the different components of variance in the measurements. But, since there were four observers and only two observation periods a day, the design of the study was not wholly balanced and therefore the components of variance could not be estimated using standard analysis of variance techniques. A programme designed for the analysis of such data was used (REML). ${ }^{19}$ This was devised by Patterson and Thompson ${ }^{20}$ and provides estimates and standard errors of the various components. The components were estimated separately for the normal and diseased subjects.

The different sources of variation examined were those due to subjects (sub), bias of observers (obs), and systematic variations between the two days (day), between sets of measurements on the same day (time), between sets of measurements on the two days (day $x$ time), and between the two legs (leg). The following non-systematic variations were estimated: interaction between the subjects and observers (sub $\times$ obs) and subjects and days (sub $x$ day), differences between a subject's left and right leg measurements (sub $\times$ leg), in the way observers measure different legs (sub $\times$ leg $x$ obs), and in day-to-day differences between legs $($ sub $\times$ leg $\times$ day). The residual variation was due to differences in repeat readings by the same observer. Observer variation in its usual sense is represented by the sum of the (sub $\times$ leg $\times$ obs) and (sub $\times$ obs) components. 
The method of calculating ankle brachial ratios ensured that both the ankle and brachial pressures for a single ratio were based on the same measurements, either first or second, within each set of measurements.

\section{Results}

In the initial analysis, mean values were calculated for all observations according to observer, day, and time (first or second set of measurements). Among diseased and healthy subjects, mean ankle and brachial systolic pressures, but not ankle brachial ratios, were higher on the first day than on the second, and for the second set of measurements than for the first (table 1). Larger pressure differences occurred between observers, particularly for brachial pressure among diseased subjects $(10 \mathrm{mmHg}$ difference between first and second observers). But differences in mean ankle brachial ratios between observers were small; the maximum difference was $\mathbf{0 . 0 3 6}$.

Readings repeated immediately by the same observer were similar. The figure, for example, shows the close correlation between first and second readings for the measurement of right ankle pressure.

Expected differences occurred between diseased and normal subjects, namely, higher brachial pressures, lower ankle pressures, and lower ankle brachial ratios among diseased subjects (table 1). But variability did not differ according to the severity of disease as indicated by the ankle brachial ratio. When the eight measurements of each parameter made on a patient were examined, the standard deviations of ankle and brachial pressures and ratios did not vary consistently according to mean ankle brachial ratios.

In the components of variance analysis (table 2), the between subject variability (sub) was by far the largest source of variation (except for the ankle brachial ratio in normals). Other sources of variation concerning the subject occurred mostly among those with disease. For example, in the measurement of ankle systolic pressure

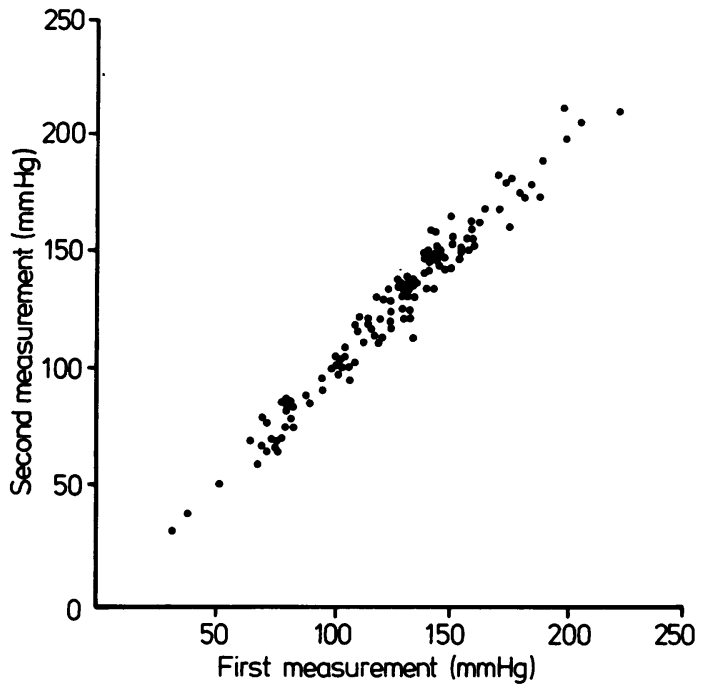

First and second right ankle systolic pressure measurements on each patient.

and ankle brachial ratio, systematic differences between the two legs (leg), measurable variation between a subject's left and right leg measurements (sub $\times$ leg), and day-to-day differences between legs (sub $\times$ leg $\times$ day) occurred only in diseased subjects. The sub $\times$ leg variation was particularly high. Variation due to interaction between subjects and observers (sub $\times$ obs) and differences between repeat readings contributed to the variability of most of the measurements. Observer variation due to interaction between subjects and observers (sub $\times$ obs) and differences in the way observers measured each leg $($ sub $\times$ leg $\times$ obs) was generally greater in diseased than in normal subjects. Observer bias (obs), however, had a moderate effect only on brachial systolic pressure in diseased subjects.

The figures in table 2 were used to estimate the precision likely to be associated with a measurement

Table 1 Mean brachial and ankle systolic pressures and ankle brachial ratios for diseased and normal subjects by observer, day, and time

\begin{tabular}{|c|c|c|c|c|c|c|c|}
\hline & & \multicolumn{2}{|c|}{$\begin{array}{l}\text { Brachial systolic } \\
\text { pressure }(\mathbf{m m H g})\end{array}$} & \multicolumn{2}{|c|}{$\begin{array}{l}\text { Ankle systolic } \\
\text { pressure }(\mathrm{mm} \mathrm{Hg})\end{array}$} & \multicolumn{2}{|c|}{$\begin{array}{l}\text { Ankle brachial } \\
\text { ratio }\end{array}$} \\
\hline & & Normals & Diseased & Normals & Diseased & Normals & Diseased \\
\hline Observer & $\begin{array}{l}1 \\
2 \\
3 \\
4\end{array}$ & $\begin{array}{l}126.4 \\
125.6 \\
124.1 \\
124.5\end{array}$ & $\begin{array}{l}141.7 \\
151.5 \\
146.4 \\
142.5\end{array}$ & $\begin{array}{l}148.5 \\
150.2 \\
145.4 \\
144.9\end{array}$ & $\begin{array}{l}106 \cdot 3 \\
108 \cdot 1 \\
104.9 \\
102 \cdot 1\end{array}$ & $\begin{array}{l}1.179 \\
1.206 \\
1.178 \\
1.170\end{array}$ & $\begin{array}{l}0.753 \\
0.719 \\
0.725 \\
0.727\end{array}$ \\
\hline Day & $\begin{array}{l}1 \\
2\end{array}$ & $\begin{array}{l}126 \cdot 8 \\
123 \cdot 6\end{array}$ & $\begin{array}{l}147 \cdot 5 \\
143 \cdot 5\end{array}$ & $\begin{array}{l}148 \cdot 5 \\
146 \cdot 0\end{array}$ & $\begin{array}{l}106 \cdot 7 \\
104 \cdot 0\end{array}$ & $\begin{array}{l}1 \cdot 177 \\
1 \cdot 189\end{array}$ & $\begin{array}{l}0.728 \\
0.733\end{array}$ \\
\hline $\begin{array}{l}\text { Time (set of } \\
\text { measurements) }\end{array}$ & $\begin{array}{l}1 \\
2\end{array}$ & $\begin{array}{l}124.8 \\
125.5\end{array}$ & $\begin{array}{l}143.9 \\
147.1\end{array}$ & $\begin{array}{l}147 \cdot 0 \\
147 \cdot 5\end{array}$ & $\begin{array}{l}104 \cdot 2 \\
106 \cdot 5\end{array}$ & $\begin{array}{l}1 \cdot 184 \\
1 \cdot 182\end{array}$ & $\begin{array}{l}0.730 \\
0.732\end{array}$ \\
\hline
\end{tabular}


Table 2 Estimates of components of variance and associated standard errors

\begin{tabular}{|c|c|c|c|c|c|c|}
\hline & \multicolumn{2}{|c|}{ Brachial systolic pressure } & \multicolumn{2}{|c|}{ Ankle systolic pressure } & \multicolumn{2}{|c|}{ Ankle brachial ratio } \\
\hline & Normals & Diseased & Normals & Diseased & Normals & Diseased \\
\hline$\overline{\text { Sub }}$ & $414(200)$ & $297(100)$ & $374(183)$ & $608(286)$ & $15 \cdot 8(15 \cdot 4)$ & $259(127)$ \\
\hline Leg & - & - & - & $64 \cdot 3(124 \cdot 8)$ & - & $38 \cdot 6(70 \cdot 6)$ \\
\hline Sub $\times$ leg & - & - & - & $525(169)$ & - & $252(79.6)$ \\
\hline Sub $\times$ day & - & $20 \cdot 4(22 \cdot 4)$ & $17 \cdot 6(11 \cdot 3)$ & $16 \cdot 4(25 \cdot 7)$ & - & - \\
\hline Sub $\times$ leg $\times$ day & - & - & - & $61 \cdot 8(27 \cdot 0)$ & - & $22 \cdot 0(8 \cdot 7)$ \\
\hline Obs (observer bias) & - & $16 \cdot 1(16 \cdot 7)$ & - & - & - & - \\
\hline Sub $x$ obs & $22 \cdot 0(10 \cdot 1)$ & $80.8(19.8)$ & - & $21 \cdot 2(12 \cdot 2)$ & $30.5(11.9)$ & $18 \cdot 8(6 \cdot 5)$ \\
\hline Sub $\times$ leg $\times$ obs & - & - & - & $14 \cdot 8(7 \cdot 1)$ & $47 \cdot 2(12 \cdot 1)$ & $15 \cdot 7(4 \cdot 9)$ \\
\hline Residual (repeat readings) & $21 \cdot 2(4 \cdot 5)$ & $22 \cdot 9(3 \cdot 3)$ & $25 \cdot 9(3.9)$ & $23 \cdot 4(2.4)$ & $31 \cdot 5(4 \cdot 7)$ & $16 \cdot 9(1 \cdot 7)$ \\
\hline
\end{tabular}

NB Variance estimates $<10$ are excluded from the table.

made under given conditions and is shown in table 3. Precision increases with the number of measurements when taken by different observers on different days. Measurement of ankle systolic pressure is slightly less precise than measurement of brachial pressure. For both ankle and brachial pressures, measurements are more accurate among normals than among diseased subjects. There is, however, only a marginal difference between normals and diseased subjects in the precision of ankle brachial ratios.

\section{Discussion}

The estimated variability in measurements of ankle systolic pressure and the ankle brachial pressure ratio (table 3) is compatible with findings in other studies. Ouriel et $a^{21}$ conducted repeat measurements on five occasions during a period of one month and found that the $95 \%$ confidence limits of a single measurement of the ankle brachial pressure ratio were mean $\pm 19 \%$. In a similar study, Baker and $\mathrm{Dix}^{22}$ concluded that a repeat measurement of the ratio would have to change by more than \pm 0.15 from the initial value for the difference to be considered statistically significant $(\mathrm{p}<0.05)$. Osmundson et al ${ }^{23}$ found that $20 \%$ of ankle brachial ratios taken 10 days apart differed by more than $\pm 0 \cdot 1$.
Less substantial variations have been noted in other studies. $^{82425}$ In one population based study, for example, a coefficient of variation of $2 \%$ was obtained for 10 repeat measurements of ankle systolic pressure on 10 subjects. $^{8}$ Differences in variability between studies may be due partly to case mix because, as observed in our study and another, ${ }^{23}$ variability differs slightly between diseased and normal subjects. Also our study was the first to examine systematically the effect of multiple observers making blind measurements using a random zero sphygmomanometer. This approach would produce greater variability than one observer taking repeat measurements using a routine sphygmomanometer.

The variability in measuring brachial systolic pressure in this study was comparable to or better than that noted in large epidemiological surveys. In the Framingham study, for example, the $95 \%$ confidence interval of one reading of systolic pressure in younger men was $\pm 13 \cdot 2 \mathrm{mmHg}{ }^{26}$ Readings of systolic pressure taken annually over four years on 722 men participating in a prospective study in London showed standard deviations of $9.1 \mathrm{mmHg}$ between visits and $7 \cdot 1 \mathrm{mmHg}$ between duplicate readings taken on the same visit. ${ }^{27}$ Furthermore, in our study, reproducibility of ankle systolic pressure and the ankle brachial ratio was almost as good as for brachial

Table 3 95\% Confidence limits of brachial and ankle systolic pressures and ankle brachial ratios measured under given conditions

\begin{tabular}{|c|c|c|c|c|c|c|}
\hline \multirow[b]{2}{*}{ Mean of: } & \multicolumn{2}{|c|}{ Brachial systolic pressure $( \pm \mathrm{mmHg})$} & \multicolumn{2}{|c|}{ Ankle systolic pressure $( \pm \mathrm{mmHg})$} & \multicolumn{2}{|c|}{ Ankle brachial ratio ( $\pm \%$ ) } \\
\hline & Normals & Diseased & Normals & Diseased & Normals & Diseased \\
\hline $\begin{array}{l}\text { One observer, one measurement } \\
\text { One observer, two repeat }\end{array}$ & $14 \cdot 0$ & $23 \cdot 8$ & $15 \cdot 7$ & $25 \cdot 8$ & 16.4 & 16.9 \\
\hline $\begin{array}{l}\text { measurements } \\
\text { Two observers, one measurement }\end{array}$ & 12.5 & $22 \cdot 9$ & $14 \cdot 0$ & $25 \cdot 0$ & $14 \cdot 4$ & $16 \cdot 0$ \\
\hline & $10 \cdot 7$ & $18 \cdot 4$ & $12 \cdot 5$ & $22 \cdot 0$ & $12 \cdot 1$ & $13 \cdot 6$ \\
\hline $\begin{array}{l}\text { each (all on same day) } \\
\text { Two observers, two measurements } \\
\text { each (one on one day and another } \\
\text { on a different day) }\end{array}$ & $\begin{array}{l}9.7 \\
8.9\end{array}$ & 17.8 & $11 \cdot 5$ & $21 \cdot 5$ & $10 \cdot 8$ & $13 \cdot 0$ \\
\hline
\end{tabular}


systolic pressure (table 3), implying an overall comparability with the reproducibility of brachial systolic pressures measured in epidemiological studies.

The main sources of variation in brachial systolic pressure, apart from that occurring between subjects, consisted of random variations between observers, different days, and repeat readings (table 2). The particularly high observer variation among the diseased subjects compared to the normals is difficult to explain. The diseased subjects did not have unusually high systolic pressures, which may be more labile, ${ }^{26}$ nor should the detection of systolic pulsation in their brachial arteries have been more difficult than in the normals. A possible explanation is that the non-systematic process of recruiting normal volunteers tended to select more stable subjects than the diseased persons recruited in the clinic. Moreover, the healthy subjects were slightly younger, and lability may increase with age. ${ }^{26}$

The sources of variation in ankle systolic pressures and ankle brachial ratios have not been studied previously in detail. The main finding of this study was that the variability attributable to observers, days, and repeat measurements was considerably less than the "biological" variability between subjects and between legs. Variation among the normals in ankle brachial pressure ratios was due mainly to random observer variation, particularly interaction between subjects and observers, and repeat measurements, with day to day variation contributing little to the overall variability. Among the diseased subjects, there was, as expected, a large subject by leg variation due to different severities of disease in each leg. The relatively large (sub $\times$ leg $\times$ day) variation in ankle systolic pressures suggests considerable differences between right and left leg measurements from day to day within subjects. The (sub $\times$ leg $\times$ obs) variation suggests that some observers had more difficulty measuring one leg than the other in some subjects. Presumably this would occur among those in whom arterial flow was difficult to detect and would be compatible with the higher variation noted in diseased than in normal subjects.

Is the variability of ankle systolic pressure and the ankle brachial ratio acceptable for research purposes? This will depend on the nature of the research. In clinical studies of a small number of subjects in which cut-off points are used to classify individuals, the confidence interval associated with a single measurement may result in considerable misclassification, and more than one measurement may be required to improve precision (table 3 ). In large epidemiological studies examining between subject variability, the additional variability due to the measurement of subjects by different observers and on different days is small relative to the between subject variability. Thus a single measurement by one observer may be adequate although greater precision may be obtained by making multiple observations. It should be appreciated, however, that variability is not a fixed phenomenon but can be kept to a minimum by setting appropriate measurement criteria and by training and testing observers.

We thank Margaret Apps, Elizabeth Cawood, Eileen Kerracher, and Felicity Smith for taking the measurements. This study was supported by a grant from The British Heart Foundation.

Correspondence to: Dr F G R Fowkes, Department of Community Medicine, University of Edinburgh, Medical School, Teviot Place, Edinburgh EH8 9AG.

\section{References}

${ }^{1}$ Mitchell JRA, Schwartz CJ. Arterial disease. Oxford: Blackwell, 1965.

2 Reid DD, Brett GZ, Hamilton PJS, Jarrett RJ, Keen H, Rose G. Cardiorespiratory disease and diabetes among middle aged male civil servants. Lancet 1974; i: 469-73.

${ }^{3}$ Hughson WG, Mann JI, Garrod A. Intermittent claudication: prevalence and risk factors. $\mathrm{Br} \mathrm{Med} J \mathrm{1987}$; 1: 1379-81.

${ }^{4}$ Department of Health \& Social Security. Office of Populations, Censuses and Surveys. Hospital in-patient enquiry. Main tables. London: Her Majesty's Stationery Office, 1986.

${ }^{5}$ Criqui MH, Fronek A, Barrett-Connor E. The prevalence of peripheral arterial disease in a defined population. Circulation 1985; 71: 510-5.

${ }^{6}$ Widmer LK, Greensher A, Kannel WB. Occlusion of peripheral arteries: a study of 6,400 working subjects. Circulation 1964; 30: 836-42.

${ }^{7}$ De Backer IG, Kornitzer M, Sobolski J, Denolin $\mathbf{H}$. Intermittent claudication-epidemiology and natural history. Acta Cardio 1979; 34: 115-24.

8 Schroll $M$, Munck $O$. Estimation of peripheral arteriosclerotic disease by ankle blood pressure measurements in a population study of 60 year old men and women. J Chron Dis 1981; 34: 261-9.

${ }^{9}$ Winsor T. Influence of arterial disease on the systolic blood pressure gradients of the extremity. Am J Med Sci 1950; 220: $117-26$

${ }^{10}$ Carter SA. Clinical measurement of systolic pressures in limbs with arterial occlusive disease. JAMA 1969; 207: 1869-74.

11 Yao ST. New techniques in objective arterial evaluation. Arch Surg 1973; 106: 600-4.

12 Hummel BW, Hummel BA, Mowbry A, et al. Reactive hyperemia vs treadmill exercise testing in arterial disease. Arch Surg 1978; 113: 95-8.

13 Bernstein EF, Fronek A. Current status of noninvasive tests in the diagnosis of peripheral arterial disease. Surg Clin North Am 1982; 62: 473-87.

${ }^{14}$ Laing S. Greenhalgh RM. The detection and progression of asymptomatic peripheral arterial disease. Br J Surg 1983; 70: 628-30. 
${ }^{15}$ Chamberlain J, Housley E, Macpherson AIS. The relationship between ultrasound assessment and angiography in occlusive arterial disease of the lower limb. Br J Surg 1975; 62: 64-7.

16 Wright BM, Dore CF. A random-zero sphygmomanometer. Lancet 1970; i: 337-8.

${ }^{17}$ Stegall HF, Karndon MB, Kemmerer WT. Indirect measurement of arterial blood pressure by Doppler ultrasound sphygmomanometry. J Appl Physiol 1968; 25: 763-8.

${ }^{18}$ Kazamias TM, Gander MP, Franklin DL, Ross J Jr. Blood pressure measurement with Doppler ultrasonic flowmeter. J Appl Physiol 1971; 30: 585-8.

19 Robinson DL. Estimation and use of variance components. Statistician 1987; 36: 3-14.

${ }^{20}$ Patterson HD, Thompson R. Maximum likelihood estimation of components of variance. Proceedings of $8 \mathrm{th}$ International Biometric Conference 1975; 197-207.

${ }^{21}$ Ouriel K, McDonnel AE, Metz CE, Zarins CK. A critical evaluation of stress testing in the diagnosis of peripheral vascular disease. Surgery 1982; 91: 686-93.
${ }^{22}$ Baker JD, Dix D. Variability of Doppler ankle pressures with arterial occlusive disease: an evaluation of ankle index and brachial-ankle pressure gradient. Surgery 1981; 89: 134-7.

${ }^{23}$ Osmundson PJ, O'Fallon M, Clements IP, et al. Reproducibility of non-invasive tests of peripheral occlusive arterial disease. J Vasc Surg 1985; 2: $26-41$.

${ }^{24}$ Gruntzig A, Schlumpf $M$. The validity and reliability of post stenotic blood pressure measurement by Doppler ultrasonic sphygmomanometry. Vasa 1974; 3: 65-71.

${ }^{25}$ Carter SA. Indirect systolic pressures and pulse waves in arterial occlusive disease of the lower extremities. Circulation 1968; 37: 624-38.

${ }^{26}$ Gordon T, Sorlie P, Kannel WB. Problems in the assessment of blood pressure: The Framingham Study. Int J Epidemiol 1976; 5: 327-34.

${ }^{27}$ Armitage P, Fox W, Rose GA, Tinker CM. The variability of measurements of casual blood pressure. II Survey experience. Clin Sci 1966; 30: 337-44.

Accepted for publication November 1987 